\title{
FREE RADICAL SCAVENGING, IMMUNOMODULATORY ACTIVITY AND CHEMICAL COMPOSITION OF LUFFA ACUTANGULA VAR. AMARA (CUCURBITACEAE) PERICARP
}

\author{
KALASKAR MOHAN G. *, SURANA SANJAY J. \\ Department of Pharmacognosy, \\ R. C. Patel institute of Pharmaceutical Education and Research, Shirpur (Dist: Dhule) MS, India, 425405. \\ Running title: Antioxidant and immunomodulatory activity of Luffa amara \\ (Received: March 7, 2013 - Accepted: January 8, 2014)
}

\begin{abstract}
The Luffa acutangula Var. amara (Cucurbitaceae) is climbing shrub; commonly known as wild ridge gourd. Its aerial parts are used traditionally in diverse health ailments. Four successive extracts of $L$. amara pericarp (LAP) were evaluated for antioxidant using in vitro for DPPH, ABTS, superoxides radical, reducing power and phosphomolybdenum assay. The bioactive ethanol extract was evaluated for immunomodulatory activity by in vivo phagocytosis using carbon clearance and neutrophil adhesion test. The bioactive ethanolic extracts showed potent in vitro antioxidant ability, increased phagocytic index $(0.028 \pm 0.002)$, and increased the $\%$ neutrophil adhesion $(24.63 \pm 0.87 \%)$. Furthermore, the potent plant phenolics such as gallic acid and $p$-hydroxybenzoic acid were isolated and identified spectroscopically. The presence of these plant phenolics and like constituents would be responsible for their potent antioxidant and immunomodulatory activity.
\end{abstract}

Keywords: Luffa acutangula var. amara, pericarp, antioxidant, immunomodulator.

\section{INTRODUCTION}

The Luffa acutangula Var. amara (LA) is climbing herb, grown in almost all hotter parts of India as common weed; commonly known as wild ridge gourd. In Ayurveda and folklore remedies, the plant used to treat different aliment. LA fruit has reported to possess the bitter principle luffin, colocynthin, and triterpenoids. The fruit showed CNS depressant effect ${ }^{1}$. The hepatoprotective activity of the leaves and fruits of an edible variety i.e. Luffa acutangula in carbon tetrachloride and rifampicin induced liver damage has been reported ${ }^{2,3}$. In the present study, we aimed to determined antioxidant and immunomodulatory activity of bioactive extract, furthermore fractionation, isolation, and identification of responsible phytoconstituents from L. amara pericarp (LAP).

\section{EXPERIMENTAL PROCEDURES}

\subsection{Plant material and extraction}

The fruits of L. amara were collected from the Shirpur and nearby area, Maharashtra, India in the month of October-November 2010. The plant identified and authenticated (PCO/LA 01) by Dr. D. A. Patil, Taxonomist, Department of Botany, S.S.V.P.S College of science, Dhule, Maharashtra, India. A Herbarium specimen deposited in Dept. of Pharmacognosy, R. C. Patel institute of Pharmaceutical Education and Research, Shirpur, Dhule. The air-dried fruits were separated as seeds and pericarp. The pericarp extracted successively with petroleum ether $\left(60-80^{\circ}\right)$ (PE), ethyl acetate (EA) and ethanol (EO) by hot continuous percolation. The resultant marc macerated with water (AQ) twice at $25^{\circ} \mathrm{C}$ for $48 \mathrm{~h}$. Extracts after filtrations were dried using a rotary evaporator (BUCHI, Rotavapor R - 215) under reduced pressure.

\subsection{Phytochemical studies}

All the extracts were standardized for total phenolic and flavonoid content as per Kalaskar and Surana ${ }^{4}$ in terms of gallic acid equivalents/g extract and quercetin equivalents/g extract, respectively. In our previous study, the presence of lipids, triterpenoids, steroids, saponins, flavonoids, phenolic acid, tannins, carbohydrates, protein, and amino acids has reported in LA Pericarp $(\mathrm{LAP})^{1}$.

\subsection{Isolation of the active constituents}

The bioactive EO extract was fractionation using silica gel column with gradient elution of hexane: chloroform and chloroform: methanol. The eight fractions(fr) of different polarity were collected. These were fr 1 (elute of hexane: chloroform; 8:2), fr 2 (elute of hexane: chloroform; 6:4), fr 3 (elute of hexane: chloroform; 4:6), fr 4 (elute of hexane: chloroform; 2:8), fr 5 (elute of chloroform: methanol; 8:2), fr 6 (elute of chloroform: methanol; 6:4), fr 7 (elute of chloroform: methanol; 4:6), and fr 8 (elute of chloroform: methanol; $2: 8)$. These fractions were evaluated for antioxidant potential using DPPH assay (Kalaskar and Surana, 2011). The bioactive fr 2 on gradual eluting with chloroform: methanol (9:1----7:3) on the silica gel column yields compound 1. Fr 8 was loaded on silica gel and further gradually eluted with chloroform: acetone (7:3 --- 4:6) yields compound 2. The spectroscopic methods were used to identify these compounds.

\subsection{Experimental animals}

Swiss albino mice (25-30 g) of either sex were used in the study. They were procured from R. C. Patel Institute of Pharmaceutical Education and Research, Shirpur, Dhule, Maharashtra, India. They were randomly distributed into groups, housed in cages ( 6 per cage), and maintained under standard conditions at $26 \pm 2^{\circ} \mathrm{C}$ and relative humidity $44-56 \%$ and $12 \mathrm{~h}$ light: $12 \mathrm{~h}$ dark cycles each day for one week before and during the experiments. All animals fed with the standard rodent pellet diet and water ad libitum. Institutional Animal Ethical Committee cleared this project.

\subsection{Antioxidant activity}

The extracts were dissolved in methanol or DMSO at a concentration $1 \mathrm{mg} / \mathrm{ml}$, further diluted to prepare the series of concentrations. Reference standard ascorbic acid was used for comparison in all assays.

\subsubsection{DPPH radical-scavenging activity}

Radical scavenging activity of plant extracts against stable DPPH was done according to the method of Ebrahimzadeh with minor modifications ${ }^{5}$. Different concentrations of each extracts were added, to an equal volume, methanolic DPPH $(100 \mathrm{mM})$ solution. Each of the extract or the reference standard solution was added separately in wells of the micro-titre plate. After $20 \mathrm{~min}$ at room temperature, the absorbance was measured at $517 \mathrm{~nm}$ using microplate spectrophotometer (BIO-Tek, USA. Model-96 well micro plate). Same procedure was followed for control by using methanol in place of extract. The percentage inhibition was estimated based on the percentage of DPPH radical scavenged using the following formula:

$\%$ Inhibition $=[($ Control absorbance - Sample absorbance $) /($ Control absorbance) $] \times 100$

\subsubsection{ABTS radical cation scavenging activity}

ABTS radical cation scavenging activity was performed using the method reported by Fellegrin with slight modifications ${ }^{6}$. In brief, ABTS solution (7 $\mathrm{mM})$ was reacted with potassium persulfate $(2.45 \mathrm{mM})$ solution and kept overnight in the dark to yield a dark colored solution containing ABTS ${ }^{+}$ radical cation. Prior to use in the assay, the ABTS radical cation was diluted with $50 \%$ methanol for an initial absorbance of about 0.700 at $734 \mathrm{~nm}$. After the addition of $1.0 \mathrm{ml}$ of diluted ABTS ${ }^{+}$to $10 \mu \mathrm{l}$ of sample, the absorbance was measured after $5 \mathrm{~min}$ of initial mixing. The percentage inhibition was calculated according to the formula:

Scavenging effect $(\%)=[($ control absorbance - sample absorbance $) /$ (control absorbance) X 100 . 
The antioxidant potential of extract was expressed as $\mathrm{IC}_{50}$, the concentration necessary for a $50 \%$ reduction of $\mathrm{ABTS} \cdot{ }^{+}$radicals.

\subsubsection{Total antioxidant capacity by phosphomolybdenum method}

The total antioxidant capacity of LAP extracts were evaluated as reported by Saleh and Hameed ${ }^{7}$. An aliquot of $100 \mu 1$ of extract solutions were combined with $1 \mathrm{ml}$ of reagent $(0.6 \mathrm{M}$ sulfuric acid, $28 \mathrm{mM}$ sodium phosphate and $4 \mathrm{mM}$ ammonium molybdate). All tubes were capped and incubated in a boiling water bath at $95^{\circ} \mathrm{C}$ for $90 \mathrm{~min}$. Tubes were allowed to cool at room temperature. Absorbance of the test and standard solutions was measured at $695 \mathrm{~nm}$ against blank containing $0.1 \mathrm{ml}$ of distilled water and $1 \mathrm{ml}$ of reagent. The standard curve for total antioxidant capacity was plotted using ascorbic acid standard solution $(20-100 \mu \mathrm{g} / \mathrm{ml})$ following after said procedure. An antioxidant capacity was expressed as milimolar equivalents of ascorbic acid.

\subsubsection{Superoxide radical-scavenging activity by Riboflavin-Light-NBT System}

The super oxide free radical scavenging activity was carried out as per Bafna and Misra with slight modification ${ }^{8}$. The $200 \mu \mathrm{l}$ of EDTA, $100 \mu \mathrm{l}$ of NBT, $50 \mu \mathrm{l}$ of riboflavin, $2.5 \mathrm{ml}$ of phosphate buffer $\mathrm{pH} 8.0$ and $200 \mu \mathrm{l}$ of varying concentration of extracts and reference standard mixed in test tubes. Reaction commenced by illuminating the reaction mixture for 15 minutes using the fluorescent lamp. After illumination, the absorbance was measured at 590 $\mathrm{nm}$. The same procedure followed for control by replacing methanol in place of samples. Ascorbic acid used as standard. The percent inhibition of superoxide anion generation calculated using the following formula:

Scavenging activity $(\%)=(1-$ absorbance of sample/absorbance of control) x 100 .

\subsubsection{Reducing power assay}

A reducing power assay was pursued by method of Oyaizu'. $2.5 \mathrm{ml}$ of extract solution, $2.5 \mathrm{ml}$ of phosphate buffer $(\mathrm{pH} 6.6)$ and $2.5 \mathrm{ml}$ potassium ferricyanide $(1 \% \mathrm{w} / \mathrm{v})$ were mixed, and incubated at $50^{\circ} \mathrm{C}$ for $20 \mathrm{~min} .2 .5 \mathrm{ml}$ of trichloroacetic acid $(10 \% \mathrm{w} / \mathrm{v})$ was added to each test tube and centrifuged at $3000 \mathrm{rpm}$ for $10 \mathrm{~min} .2 .5 \mathrm{ml}$ of supernatant was mixed with $2.5 \mathrm{ml}$ of water and $0.5 \mathrm{ml}$ of ferric chloride $(0.1 \% \mathrm{w} / \mathrm{v})$ and absorbance was measured at $700 \mathrm{~nm}$. Increase absorbance of the reaction mixture indicated high reducing power.

\subsection{Immunomodulatory activity}

\subsubsection{In vivo phagocytosis using carbon clearance}

The phagocytic activity was determined as per reported method ${ }^{10}$. Swiss albino mice were treated with EO LAP extracts $(100$ and $200 \mathrm{mg} / \mathrm{kg}$ ) in treated groups. The control group received vehicle (water), while standard group treated with levamisole at dose $25 \mathrm{mg} / \mathrm{kg}$ for 5 days orally. After $48 \mathrm{~h}$ of the last dose on $5^{\text {th }}$ day, mice were injected with $0.1 \mathrm{ml}$ of Indian ink intravenously through tail vein. Blood samples were collected from retro-orbital plexus just before and at 0 and $15 \mathrm{~min}$ after injection. Blood samples were lyzed with $2 \mathrm{ml}$ of $0.1 \%$ sodium carbonateand absorbance of samples recorded at $660 \mathrm{~nm}$. The phagocytic index was calculated using the formula

Phagocytic index $=\mathrm{k}$ (sample) $/ \mathrm{k}$ (control)
Where $\mathrm{K}=($ LogeOD1 - LogeOD2) $/ 15$

$\mathrm{OD} 1=$ optical densities at 0 minutes and, OD2= optical densities at 15 minutes, respectively.

\subsubsection{Neutrophil adhesion test}

The method described by Wilkonson was used for evaluating the effect of extracts on neutrophil adhesion ${ }^{11}$. Rats of group I served as Control and received only vehicle $10 \mathrm{ml} / \mathrm{kg}$ normal saline, group II was received standard drug (levamisole) at dose $25 \mathrm{mg} / \mathrm{kg}$. Whereas group III, and IV were pretreated with different concentration of LAP EO extract (100 and $200 \mathrm{mg} /$ $\mathrm{kg}$ ) orally. On the 14th day of drug treatment, blood samples were collected by puncturing the retro-orbital plexus into heparinized vial and analyzed for total leucocyte counts (TLC) and differential leucocyte counts (DLC). After initial counts, blood samples were incubated with nylon fibers for $15 \mathrm{~min}$ at $37^{\circ} \mathrm{C}$. The incubated blood samples were again analyzed for TLC and DLC. The product of TLC and percentage Neutrophil gives Neutrophil index (NI) of blood sample. Percent neutrophil adhesion was calculated as shown below

\section{Neutrophil adhesion $(\%)=\{(\mathrm{NIu}-\mathrm{Nit}) / \mathrm{Niu}\} \mathrm{X} 100$}

Where, $\mathrm{NIu}=$ Neutrophil index of untreated blood sample and NIt $=$ Neutrophil index of treated blood sample.

\subsection{Statistical analysis}

Results were expressed as mean \pm SEM. Data were analyzed using One way analysis of variance (ANOVA) followed by Dunnett test. Value of $\mathrm{p}<0.05$ was considered to be statistically significant.

\section{RESULTS}

In the present study, the LAP extracts were evaluated for total phenolic and total flavonoid content. The petroleum ether $\left(60-80^{\circ}\right)(\mathrm{PE})$, ethyl acetate (EA) and ethanol (EO) and water (AQ) extract showed the total phenolic content as $3.85 \pm 0.08,21.26 \pm 0.8,32.48 \pm 0.24$, and $21.73 \pm 0.33$; while total flavonoid content were $4.8 \pm 0.11,89.86 \pm 2.75,73.64 \pm 1.13$ and $19.34 \pm 0.27$, respectively. The ethanol extract showed maximum phenolic content $(32.48 \pm 0.24)$ while ethyl acetate extract contains highest flavonoids $(89.86 \pm 2.75)$ among the extracts.

The antioxidant activity of extracts was evaluated with the help of different antioxidant assay. The extracts exhibited significant antioxidant activity in the $\mathrm{DPPH}, \mathrm{ABTS}$ assays. The $\mathrm{IC}_{50}$ value obtained for DPPH, ABTS scavenging of ethanol extract was $84.00 \pm 0.76$ and $43.76 \pm 0.62 \mu \mathrm{g} / \mathrm{ml}$ which was found least among all extracts and comparable to the reference standard ascorbic acid $\left(\mathrm{IC}_{50}\right.$ $=41.89 \pm 0.36$ and $12.16 \pm 0.04 \mu \mathrm{g} / \mathrm{ml})$. The total antioxidant capacity of ethanol extracts (equivalent to ascorbic acid) found to be highest $(30.72 \pm 0.73 \mu \mathrm{g} /$ $\mathrm{ml}$ ). In super oxide radical scavenging assay, the petroleum ether and aqueous extracts showed least while ethyl acetate and ethanol extract showed highest scavenging ability similar to DPPH assay. It was found that the reducing power increased with the concentration of test extracts. The LAP extracts exhibited a good reducing power. The ethyl acetate and ethanol extracts exhibit maximum reducing of $0.615 \pm 0.058$ and $0.512 \pm 0.004$ at $0.80 \mathrm{mg} / \mathrm{ml}$ for, respectively (Table 1).

Table 1: The extractive yields, total phenolic (gallic acid equivalent), total flavonoid (as quercetin equivalent) content, and antioxidant effect ( $\mathrm{IC}_{50}$ ) of extracts of L. amara pericarp.

\begin{tabular}{|c|c|c|c|c|c|}
\hline \multirow[b]{2}{*}{ Plant extracts } & \multirow{2}{*}{$\begin{array}{c}\text { Reducing power } \\
\text { at } \\
700 \mathrm{~nm} \\
(800 \mu \mathrm{g} / \mathrm{ml})\end{array}$} & \multirow[b]{2}{*}{$\begin{array}{l}\text { Total antioxidant } \\
\text { capacity (AAE) }\end{array}$} & \multicolumn{3}{|c|}{$\mathrm{IC}_{50}(\mu \mathrm{g} / \mathrm{ml})$} \\
\hline & & & $\begin{array}{c}\text { Scavenging } \\
\text { ability on DPPH } \\
\text { radicals }\end{array}$ & $\begin{array}{c}\text { Scavenging } \\
\text { ability on super } \\
\text { oxide } \\
\end{array}$ & $\begin{array}{c}\text { Scavenging } \\
\text { ability on ABTS } \\
\text { radicals }\end{array}$ \\
\hline $\mathrm{PE}$ & $0.451 \pm 0.006$ & $13.22 \pm 0.50$ & $474.28 \pm 1.75$ & $319.79 \pm 0.55$ & $56.76 \pm 0.15$ \\
\hline EA & $0.615 \pm 0.004$ & $28.22 \pm 0.37$ & $232.02 \pm 0.84$ & $75.23 \pm 0.43$ & $46.00 \pm 0.30$ \\
\hline EO & $0.512 \pm 0.006$ & $30.72 \pm 0.73$ & $84.00 \pm 0.76$ & $77.69 \pm 0.06$ & $43.76 \pm 0.62$ \\
\hline $\mathrm{Aq}$ & $0.488 \pm 0.003$ & $20.72 \pm 0.37$ & $414.83 \pm 2.56$ & $109.18 \pm 1.20$ & $49.26 \pm 0.32$ \\
\hline AsA & $0.782 \pm 0.006$ & ----- & $41.89 \pm 0.36$ & $20.72 \pm 0.07$ & $12.16 \pm 0.04$ \\
\hline
\end{tabular}

Each value in the table is represented as mean $\pm \operatorname{SEM}(n=3)$ PE-Pet ether $\left(60-80^{\circ}\right)$ extract; EA-Ethyl acetate extract; EO- Ethanol extract; Aq- Aqueous extract; AsA- Ascorbic acid. 
In the series of antioxidant assay, ethanol extracts revealed high antioxidant potential, thus in vivo immunomodulatory activity was assessed for EO LAP. The phagocytic index of the control group was found to be $0.006 \pm 0.001$; while administration of EOLAP in Indian ink intoxicated mice led to increase in phagocytosis to $0.028 \pm 0.002(\mathrm{P}<0.01)$ which is comparable with standard (levamisole) i.e. $0.035 \pm 0.009$ (Table 2). This test results was an indicative of immunostimulation.
The \% neutrophil adhesion in control group animals was $8.51 \pm 0.66$, whereas, in ethanolic extract-treated groups it was found with increased $(24.63 \pm 0.87)$ pattern as compared to the standard groups $(23.58 \pm 0.46)$. The ethanolic extract showed the neutrophil adhesion in dose dependent manner, suggesting possible immunostimulant action of L. amara (Table 2).

Table 2: Effect of LAP extracts on neutrophil adhesion test and phagocytic index.

\begin{tabular}{|c|c|c|c|c|c|c|c|c|}
\hline \multirow[t]{2}{*}{ Treatment /Dose } & \multicolumn{2}{|c|}{$\operatorname{TLC}\left(10^{3} / \mathrm{mm}^{3}\right)(\mathrm{A})$} & \multicolumn{2}{|c|}{ Neutrophil \% (B) } & \multicolumn{2}{|c|}{$\begin{array}{l}\text { Neutrophil index } \\
\qquad(A \times \text { B) }\end{array}$} & \multirow{2}{*}{$\begin{array}{c}\text { Neutrophil } \\
\text { adhesion }(\%)\end{array}$} & \multirow{2}{*}{$\begin{array}{l}\text { Phagocytic } \\
\text { index }\end{array}$} \\
\hline & UB & FTB & UB & FTB & UB & FTB & & \\
\hline Control (Vehicle) & $6.6 \pm 0.04$ & $6.42 \pm 0.06$ & $50.4 \pm 0.51$ & $47.4 \pm 0.24$ & $332.64 \pm 4.09$ & $304.26 \pm 1.67$ & $8.51 \pm 0.66$ & $0.006 \pm 0.001$ \\
\hline $\begin{array}{c}\text { Standard } \\
\text { (Levamisol) }\end{array}$ & $7.48 \pm 0.09$ & $7 \pm 0.06$ & $63.4 \pm 0.51$ & $51.8 \pm 1.02$ & $474.26 \pm 7.08$ & $362.38 \pm 4.68$ & $23.58 \pm 0.46^{\mathrm{a}}$ & $0.035 \pm 0.009^{\mathrm{a}}$ \\
\hline EO LAP 100 & $6.6 \pm 0.08$ & $6.06 \pm 0.05$ & $58.6 \pm 0.51$ & $53.2 \pm 0.97$ & $386.78 \pm 6.26$ & $322.24 \pm 4.15$ & $16.66 \pm 0.79^{a}$ & $0.013 \pm 0.002^{\mathrm{d}}$ \\
\hline EO LAP 200 & $7.18 \pm 0.09$ & $6.48 \pm 0.04$ & $61.8 \pm 0.66$ & $51.6 \pm 0.81$ & $443.52 \pm 2.41$ & $334.26 \pm 3.64$ & $24.63 \pm 0.87^{\mathrm{a}}$ & $0.028 \pm 0.002^{b}$ \\
\hline
\end{tabular}

Values are mean \pm SEM, $n=6$. EO LAP: ethanol extract of Luffa amara pericarp; UB: untreated blood; FTB: fiber treated blood.

${ }^{\mathrm{a}} \mathrm{P}<0.05$ significant; ${ }^{\mathrm{b}} \mathrm{P}<0.01 ;{ }^{\mathrm{c}} \mathrm{P}<0.05 ;{ }^{\mathrm{d}} \mathrm{P}>0.05$ significant

Based on the biological activity, the ethanol extract was found to be most efficacious and further processed for fractionation and isolation of bioactive constituents. The fractions evaluated for antioxidant potential with the help of DPPH assay. Among the eight fractions, fr- 2 and fr- 8 were shown the $\mathrm{IC}_{50}$ less than $100 \mu \mathrm{g} / \mathrm{ml}$ i.e. 70 and $79.43 \mu \mathrm{g} / \mathrm{ml}$, when compared with standard ascorbic acid $(35.57 \mu \mathrm{g} / \mathrm{ml})$, while other fractions showed $\mathrm{IC}_{50}$ more than 100 $\mu \mathrm{g} / \mathrm{ml}$. Thus, fraction 2 and 8 were processed for isolation of phytoconstituents. The fr- 2 and fr- 8 yields compound 1 and 2 , which were identified as $p$-hydroxybenzoic acid and gallic acid, spectroscopically.

Compound 1 ( $p$-hydroxybenzoic acid): Isolated from fraction 2 as white crystalline solid powder. UV max: 223, 311, EI-MS: m/z \% 138, 120, 92, 6, 53; melting point: $236-238^{\circ} \mathrm{C}$

Compound 2 (gallic acid): isolated form fraction 8 as white powder. UV max: 274. ${ }^{1} \mathrm{H}-\mathrm{NMR} \delta: 7.92(\mathrm{~s}$, carboxylic $\mathrm{O}-\mathrm{H}) ;{ }^{13} \mathrm{C}-\mathrm{NMR} \delta: 170.72(\mathrm{~s}, \mathrm{C}-7)$, 163.78 (s, C-3, 5), 133.26 (s, C-4), 122.59 (s, C-1) and 116.25 (s, C-2, 6); EIMS: $\mathrm{m} / \mathrm{z} \% 171[\mathrm{M}]^{+}$; melting point: $234-237^{\circ} \mathrm{C}$

\section{DISCUSSION}

The increasing evidence suggests that oxidative damage has great impact on immune system of humans. Free radical components have a relevant pathophysiological role in several types of autoimmune human diseases such as heart failure, shock, atherosclerosis, Alzheimer's disease etc ${ }^{12,13}$. It is essential to counteract this oxidative stress and thereby enhance immunity of body system. The immunomodulatory agents are being used as adjuvant therapy in oxidative stress induced various diseases or vice versa. A very few modern medicines are available to treat the oxidative stress and immunesenescence; which are costly and posses serious side effect. On the contrary, the natural antioxidants are safer choice in the treatment of oxidative stress and immunesenescence.

In the present study, an important plant of indigenous system of Indian medicine $L$. amara pericarp was explored for their antioxidant and immunomodulatory activity. The polyphenolic compounds, which contain hydroxyl groups in their structure, are responsible for antioxidant property ${ }^{14}$. The total flavonoids and phenolic contents in ethanol and ethyl acetate fractions were significantly higher than petroleum ether and water extracts. Therefore, it can presume that the major polyphenolic compounds present in these extracts.

The DPPH and ABTS radicals enabling the determination of antioxidant capacity of both hydrophilic and lipophilic compounds ${ }^{15}$. Superoxide radicals are very harmful cellular component, can cause tissue or DNA damage leads to various diseases, therefore it always recommended to measure comparative interceptive ability of antioxidant extract to scavenge superoxide molecule ${ }^{16}$. The phosphomolybdenum assay is a quantitative method to evaluate watersoluble and fat-soluble antioxidant capacity (total antioxidant capacity), in which transforming of relative free radical species MO (VI) into more stable MO (V) non-reactive products occurs ${ }^{17}$. The ethanol extract of LAP showed highest reducing ability by chelating ferrous ion effectively. The ethanol extract was found to be most efficacious in all in vitro assays; it may be due to presence of phenolics in this extract ${ }^{18}$.

Immunological agents of plant origin enhance the immune responsiveness of an organism against a pathogen by non-specifically activating the immune system. When reticulo-endothelial (RES) system is stimulated, there is increase in number of phagocytic cells, which engulf the antigens, indicating increase in immunity ${ }^{19}$. Phagocytosis represents is an important immune defense mechanism in which leukocytes ingest pathogenic microorganisms, malignant cells, tissue debris and inorganic particles (carbon ink). The in vitro phagocytosis test was carried out to evaluate the effect of the extracts on the RES. When colloidal carbon particles injected directly into system circulation, it is cleared by RES, involving phagocytes. Increase of carbon clearance is an indicator of enhanced in vivo phagocytic activity. The ethanolic LAP extracts appeared to enhance the phagocytic function by exhibiting a dose dependent increase in carbon clearance rate by the cells of RES.

Neutrophil plays an important role in enhancing immunity of the body against microbial infection by chemotaxins, phagocytosis, exocytosis, and both intracellular and extra cellular killing ${ }^{19}$. In the present study, EO-LAP at dose $200 \mathrm{mg} / \mathrm{kg}$ evoked significantly increase in \% neutrophils. The gallic acid and $p$-hydroxybenzoic acid were isolated and spectroscopicaly confirmed from the bioactive ethanol extract ${ }^{20,21}$. These phytoconstituents has a definite antioxidant potential mainly due to the strong reducing power and could have a role as a physiological antioxidant ${ }^{22,23}$. Perhaps, $p$-hydroxybenzoic acid, gallic acid and other related phenolic compounds present in $L$. amara pericarp may be responsible for its observed antioxidant and immunomodulatory activity.

\section{CONCLUSIONS}

From present investigation, it can be conclude that L. amara pericarp exhibit high antioxidant and immunostitmulant capability. This activity is attributed to high levels of total polyphenolic compounds particular to $p$-hydroxybenzoic acid and gallic acid. Further scientific work is needed to ensure the other medicinal properties of the plant in correlation to antioxidant and immunostitmulant activity.

\section{ACKNOWLEDGEMENTS}

The authors would like to thank Prof. Dr. D. A. Patil from the Prof, Dept of Botany, SSVPS College, Dhule, MS. for the identification of the plant. 


\section{REFERENCES}

1. M. G. Kalaskar, S. J. Surana, Int. J. PharmTech. Res. 2, 1609, (2010)

2. I. Ulaganathan, D. Divya, K. Radha, T.M. Vijayakumar, M.D. Dhanaraju, Res. J. Bio. Sci. 5(9), 615, (2010)

3. V. B. Jadhav, V. N. Thakare, A. A. Suralkar, A. D. Deshpande, S. R. Naik, Indian J. of Exp. Biol. 48, 822, (2010)

4. M. G. Kalaskar, S. J. Surana, J. Nat. Med. 65(3-4), 633, (2011)

5. M. A. Ebrahimzadeh, S. M. Nabavi, S. F. Nabavi, F. Bahramian, A. R. Bekhradnia, Pak. J. Pharm. Sci. 23, 29, (2010)

6. N. Fellegrin, R. Ke, M. Yang, C. Rice-Evans, Method. Enzymol. 299, 379, (1999)

7. E.S. Saleh, A. Hameed, Food Chem. 114, 1271, (2009)

8. A.R. Bafana, S. H. Mishra, Ars. Pharmaceutica. 46, 125, (2004)

9. M. Oyaizu, Jpn. J. Nutr. 44, 307, (1986)

10. A. R. Bafana, S. H. Mishra, Ars. Pharmaceutica. 45 (17), 281, (2001)

11. P.C. Wilkinson in Neutrophil adhesion test. Handbook of Experimental Pharmacology I, Vane, J.K., Ferreria, S.H. (Eds.), $1^{\text {st }}$ edition, Springer Verlag, Berlin, 1978; pp. 109.

12. B. N. Ames, M. K. Shigenaga, T. M. Hagen, Proceedings of the Natural
Academy of Sciences, USA 90, 7915, (1993).

13. K. Sudha, A.V. Rao, S. Rao, A. Rao, Neurol. India. 51(1), 60, (2003)

14. J. Javanraedi, C. Stushnoff, E. Locke, J. M. Vivanco, Food. Chem. 83, $547,(2003)$

15. L. M. Magalha, M. A. Segundo, S. Reis, J. L. Lima, Anal. Chim. Acta. $613,1,(2008)$

16. T. Vani, M. Rajani, S. Sarkar, C. J. Shishoo, Int. J. Pharmacog. 35, 313, (1997)

17. G. K. Jayaprakasha, B. Girennavar, B. S Patil,. Bioresource. Technol. 99, 4484, (2008)

18. N. Povichit, A. Phrutivorapongkul, M. Suttajit, C. Chaiyasut, P. Leelapornpisid, Pak. J. Pharm. Sci. 23, 403, (2010)

19. B. V. Ghule, G. Muruganathan, P. D.Nakhat, P. Yeole, J. Ethnopharmacol. 108, 311, (2006)

20. O. A. Eldahshan, Cur. Res. J. Biol. Sci. 3(1), 52, (2011)

21. J. G. Kang, J. H. Hur, B. S. Yun, I. D. Yoo, K. Y. Kang, Agr. Chem. Biotechnol. 46(1), 33, (2003)

22. S.B. Lotito, C. G. Fraga, Biofactors. 10, 125-130, (1999).

23. G. C. Yen, P. D. Duh, H. L. Tsaia, Food. Chem. 79, 307, (2002) 